Technical Article

\title{
Heliconias with pendent inflorescences as cut flowers
}

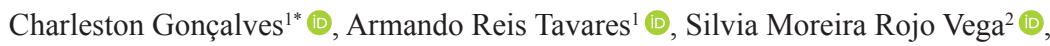 \\ Daniela Merida $^{3}$ (D), Carlos Eduardo Ferreira de Castro $^{1}$ (C) \\ ${ }^{1}$ Instituto Agronômico (IAC), Campinas-SP, Brazil. \\ ${ }^{2}$ Polo Regional do Vale do Paraíba-UPD de Ubatuba/APTA, Ubatuba-SP, Brazil. \\ ${ }^{3}$ Engenheira Agrônoma. Brazil.
}

\begin{abstract}
The Heliconia species with pendent inflorescences and colorful bracts are a good option as a cut flower for floriculture market, but only a few species of this type of Heliconia eg. H. rostrata, H. rauliniana and H. chartacea are commercially produced in Brazil. This study was carried out to characterize 36 Heliconia accessions, with pendent inflorescences, to be used as cut flower, intending to increase knowledge and use of these exceptional plants among tropical flower enthusiasts and consumers. The evaluations were performed on plants of the Germplasm Collection of the Instituto Agronômico (IAC) growing in shade, partial shade or full sun conditions. Qualitative and quantitative characteristics, related to clump growth and flower stem aspects were analyzed. A point scoring system was used to determine the species most suitable for cut flower utilization. All evaluated genotypes reached enough points to be considered suitable for use as cut flowers, even those with large inflorescences and bracts arranged in different planes, facts that affect and limit handling, packaging and transportation. H. mariae, H. fernandezii, H. platystachys, H. rauliniana, $H$. rostrata, H. standley, H. necrobracteata and H. laxa were considered outstanding. This characterization and scoring system were important to facilitate the selection of heliconia genotypes for use as cut flowers.
\end{abstract}

Keywords: heliconias, scoring system, selection, tropical flowers, tropical plants.

\section{Resumo}

Helicônias com inflorescências pendentes como flores de corte

As espécies de Heliconia com inflorescências pendentes e brácteas coloridas são uma boa opção para o mercado de flores de corte, mas apenas algumas espécies de Heliconia, por exemplo. H. rostrata, H. rauliniana e H. chartacea, são comercialmente produzidas no Brasil. Este estudo foi realizado para caracterizar 36 acessos de diferentes espécies, com inflorescências pendentes para serem utilizadas como flor de corte, visando a aumentar o conhecimento e a utilização destas plantas excepcionais pelos consumidores e entusiastas das flores tropicais. As avaliações foram realizadas em plantas da Coleção de Germoplasma do Instituto Agronômico (IAC) Ubatuba, São Paulo, Brasil, crescendo em condição de sombra, sombra parcial ou pleno sol. Foram analisadas características qualitativas e quantitativas relacionadas ao crescimento da touceira e características da haste floral. Um sistema de pontuação foi usado para determinar as espécies mais adequadas para a utilização de flores de corte. Todos os genótipos avaliados foram adequados para serem usados como flores de corte, mesmo as de inflorescências grandes e brácteas dispostas em vários planos, fatos que afetam ou dificultam o manuseio, embalamento e transporte. H. mariae, H. fernandezii, H. platystachys, H. rauliniana, H. rostrata, H. standley, H. necrobracteata e H. laxa foram considerados excelentes. Esta caracterização e sistema de pontuação foram importantes para facilitar a seleção de genótipos de helicônias como flores de corte.

Palavras-chave: helicônias, sistema de pontuação, seleção, flores tropicais, plantas tropicais.

\section{Introduction}

The number of accepted species in Heliconia genus, valid in the Index Kewensis is 203 (Govaerts et al., 2016). Intragenic classifications, compiled by Andersson (1981;
1985) and Kress et al. (1999) subdivide Heliconia into the subgenera Taeniostrobus (4 species), Heliconia (43 species in 6 Sections), Stenochlamys (56 species in 6 Sections, Heliconiopsis (6 species) and Griggsia (94 species in 11 Sections). The first four subgenus comprise species

*Corresponding author: charleston.goncalves@sp.gov.br 
with upright inflorescences, Heliconiopsis comprises species with upright inflorescences and also with pendent inflorescences and Griggsia with pendent inflorescences species only.

Heliconia is an ornamental plant with exotic style (Linares-Gabrie et al., 2019), known as lobsters' claw, parrots flower, parrot's plantain, or false plantains (Buzard, 2019). Its ornamental appeal as cut flowers can be attributed to the attractive bracts that frame and protect the flowers, with several shapes and intense colors, often with contrasting colors that increase their acceptance by the consumer. However, although several species have great potential for use as cut flowers, just a few species have been cultivated for this purpose (Castro, 1995; Loges et al., 2014).

Heliconia species for cut flowers use should have small, light and, upright inflorescences, with a long postharvest durability and with reduced diameter stems. Species with pendent inflorescences have an extra high market value, but could presents packaging difficulties (Watson and Smith, 1979), due its forms and dimensions. Long and wide flowers are directly related to packaging and transportation processes, once they may be damage by scrap among bracts and impacts from the package (Araújo et al., 2018). These characteristics, in part, explain the predominant trade of heliconias with upright inflorescences compared to the species with pendent inflorescences. In addition, the minor commercialization is also due to packaging complexities, once pendent inflorescences are large and heavy, and due to the lack of knowledge of the diversity of Heliconia species with inflorescences of this kind, which are similar in number to species with upright inflorescences.

Scheme of evaluation of some heliconia species as suitable for cut flower, using a scoring point system (Castro, 1993). This system considers that the use of heliconias as a cut flower results from the consumers' demand and the observation of characteristics, such as stem size and floral inflorescence, shape, size, vigor, distribution, presence of wax and/ or hairiness in the bracts, abscess of bract flowers, number of inflorescences per plant in the crop cycle and durability of inflorescences. These characteristics affect the inflorescence harvest, handling and packaging, transport and storage. The stems of inflorescences, of most species of heliconias, are kept only in clean water with or without phenolic foam, composing all kinds of decorative arrangements, of short or long durability (Castro, 1995; Castro et al., 2007; Castro et al., 2011; Loges et al., 2014; Loges et al., 2016).

The expansion of the tropical floriculture market is based on the beauty, exoticism, and post-harvest longevity of cut flowers (Dias, 2016). This market niche, of economic importance in tropical countries, has a constant demand for new products, so the objective of this work was to evaluate 36 species of heliconias with pendent inflorescences and to test indicators for the characterization and selection of cut inflorescences, not yet introduced in commercial crops.

\section{Material and methods}

Accessions clumps, with five years of cultivation, of 36 heliconias species with pendent inflorescences were evaluated (Table 1). 
Table 1. Heliconia species evaluated in the experiment with pending inflorescences.

\begin{tabular}{|c|c|c|c|}
\hline 1 & H. chartacea Lane ex Barreiros & 19 & H. obscura Dodson \& Gentry \\
\hline 2 & $\begin{array}{l}\text { H. colgantea } \text { R.R. Smith } \\
\text { ex Daniels \& Stiles }\end{array}$ & 20 & H. pendula Wawra \\
\hline 3 & H. collinsiana Griggs & 21 & H. penduloides Loes. \\
\hline 4 & H. combinata Abalo \& Morales & 22 & H. platystachys Baker \\
\hline 5 & H. dielsiana Loes. & 23 & H. pogonantha Cufod. \\
\hline 6 & H. fernandezii Abalo \& Morales & 24 & H. ramonensis Daniels \& Stiles \\
\hline 7 & H. flabellata Abalo \& Morales & 25 & H. rauliniana Barreiros \\
\hline 8 & H. griggsiana L.B. Smith & 26 & H. regalis L. Anderss. \\
\hline 9 & H. huilensis Abalo \& Morales & 27 & H. reptans Abalo \& Morales \\
\hline 10 & H. juruana Loes & 28 & H. revoluta (Griggs) Standley \\
\hline 11 & H. laxa Abalo \& Morales & 29 & H. rostrata R.P. \\
\hline 12 & H. longissima Abalo \& Morales & 30 & H. standleyi Macbr. \\
\hline 13 & H. magnifica Kress & 31 & H. stella-maris Abalo \& Morales \\
\hline 14 & H. marginata (Griggs) Pittier & 32 & H. stilesii Kress \\
\hline 15 & H. mariae Hook. F. & 33 & H. trichocarpa Daniels \& Stiles \\
\hline 16 & H. mutisiana Cuatrec. & 34 & H. vellerigera Poepp. \\
\hline 17 & H. necrobracteata Kress & 35 & H. villosa $\mathrm{K} 1$. \\
\hline 18 & H. nutans Woodson & 36 & H. xanthovillosa Kress \\
\hline
\end{tabular}

The accessions used on the study are part of the Germplasm Bank of Ornamentals Zingiberales of IAC/ APTA in the Research and Development Unity of Ubatuba $\left(23^{\circ} 26^{\prime} 02^{\prime \prime} \mathrm{S}-45^{\circ} 04^{\prime} 16^{\prime \prime} \mathrm{W}\right)$ with annual rainfall of 2,700 $\mathrm{mm}$ and 6 meters above sea, located in the municipality of Ubatuba, São Paulo State, Brazil. Soil moisture was assessed as extremely high (swampy or waterlogged), high (edge of streams) or medium.

The plants were cultivated under full sun, half or intense shade, medium humidity soils, humid sites near streams or extremely humid sites with a tendency to soil soak in certain seasons. Other subsequent evaluations or measurements as plant height, formation of clumps with area, flowering season, and number of flowers, and inflorescences/cycle, provided the data of the general characteristics of the plants, cultivation environment and production of inflorescences.

The plant height comprised the distance between the base of the stems and the apex of the highest leaf. Clump formation considered the area occupied by the plant and was classified as small (less than $1 \mathrm{~m}^{2}$ ), medium (between 1 and $2 \mathrm{~m}^{2}$ ) or large (greater than $2 \mathrm{~m}^{2}$ ). The preferential exposure was identified as being full sun, half shade or shade. The 
flowering season comprised the time between the emission of the first inflorescence/clump and the appearance of the first signs of senescence of the last inflorescence emitted in the clump/cycle. The number of inflorescences/cycle was the total number of inflorescences developed in the clump during the flowering period.
Data were collected for three years, regarding the characteristics of the inflorescences described in Table 2. The data were compared with information available in the literature concerning the original description of the species to identify anomalies during the development process.

Table 2. Classification of the characteristics of heliconias inflorescences.

\begin{tabular}{|c|c|c|c|c|}
\hline Inflorescences & \multicolumn{4}{|c|}{ Classification } \\
\hline Inflorescence length & \multicolumn{2}{|c|}{ small (up to $0.80 \mathrm{~m}$ ), } & $\begin{array}{c}\text { medium } \\
(0.81 \text { and } 1.50 \mathrm{~m})\end{array}$ & large (above $1.51 \mathrm{~m}$ ) \\
\hline \multicolumn{5}{|l|}{ Number of bracts } \\
\hline Plan of insertion of bracts & \multicolumn{2}{|c|}{ same plan } & \multicolumn{2}{|c|}{ different plan } \\
\hline Overlapping of bracts & \multicolumn{2}{|c|}{ free } & \multicolumn{2}{|c|}{ overlapping bracts } \\
\hline Type and color of the rachis & \multicolumn{2}{|c|}{ straight and predominant color } & \multicolumn{2}{|c|}{ sinuous and predominant color } \\
\hline $\begin{array}{l}\text { Length of intermediate bracts } \\
\qquad(\mathrm{cm})\end{array}$ & small (up to 10.0) & $\begin{array}{l}\text { medium (between } \\
10.1 \text { and } 20.0 \text { ) }\end{array}$ & $\begin{array}{l}\text { large (between } 20.1 \text { and } \\
\qquad 30.0 \mathrm{~cm} \text { ) }\end{array}$ & $\begin{array}{l}\text { very large (over } 30.1 \\
\mathrm{~cm})\end{array}$ \\
\hline \multicolumn{5}{|l|}{ Number of flowers per bract } \\
\hline Hairiness of bracts & \multicolumn{2}{|c|}{ very hairy } & little hairy & without hair \\
\hline Waxiness of bracts & \multicolumn{2}{|c|}{ very waxy } & little waxy & without wax \\
\hline \multicolumn{5}{|l|}{ Color of the bracts } \\
\hline $\begin{array}{c}\text { Diameter of the floral stem }(\mathrm{cm}) \\
\text { taken } 70 \mathrm{~cm} \text { below the insertion } \\
\text { of the inflorescence }\end{array}$ & \multicolumn{2}{|c|}{ thin (up to 1.0 ) } & $\begin{array}{c}\text { medium } \\
\text { (between } 1.1 \text { and 3.0) }\end{array}$ & large (above 3.1) \\
\hline Stem firmness & \multicolumn{2}{|c|}{ firm } & intermediate & flaccid \\
\hline Height of the floral stem and & \multicolumn{2}{|c|}{ light (up to $200.0 \mathrm{~g}$ ) } & $\begin{array}{l}\text { medium (between } 200.1 \\
\text { and } 500.0 \mathrm{~g} \text { ) }\end{array}$ & $\begin{array}{l}\text { heavy (above } 500.0 \\
\text { g) }\end{array}$ \\
\hline
\end{tabular}

The selection of a species suitable for commercialization as a cut flower was made by points attribution to the characteristics stem firmness, flowering period, inflorescence production in each cycle, average post-harvest durability of the inflorescence, visual impact, suitability for handling and harvesting, packaging and transport, and resistance to transport.

The stem firmness stiffness characteristic considered were firm (4 points), floral stems with medium resistance to tipping(2 points)and fragilefloralstemswithtipping(0point). The flowering period considered 3 scoring ranges long period (over 4 months - 4 points); medium (between 2 and 4 months - 2 points) and short (up to 2 months - 1 point). The production of inflorescences per clump was classified as high (more than 30 inflorescences/clump 3 points), medium (between 15 and 30 inflorescences/ clump - 2 points) and low (less than 15 inflorescences/ clump - 1 point). The post-harvest durability of the inflorescences was evaluated by compiling the number of days in which inflorescences harvested and kept in water, remained in perfect condition and were classified as high (over 12 days - 6 points), medium (between 7 and 12 days - 4 points) and low (below 7 days - 2 points). The inflorescence was considered to be in a perfect state of conservation when the general appearance of recently harvested was maintained, with turgor, brightness, without signs of browning on the bracts, no stem tipping and with axis and pointer maintaining its original position. Signs of senescence were noted daily. The purchase impulse to acquire fresh inflorescences, estimated by 50 evaluators, were defined by a buying tendency measurement scale as high (above $80 \%$ - 3 points), medium (between 79 and $50 \%$ - 2 points), low (between 49 and $20 \%-1$ point) or nonexistent (between 19 and $0 \%$ - 0 points). The attributes and requirements of inflorescence manipulation were defined to identify the ease of handling and harvesting, transportation, packaging, and resistance to transportation. The ideal inflorescences for handling were those that meet the characteristics ( 1 point for each) inflorescences in a single plane, inflorescences with little or without hairiness, inflorescences with little or without wax, inflorescences of medium or small size, inflorescences with medium or small sized intermediate bracts; light or intermediate inflorescences; less than 10 flowers in bracts; thin or intermediate floral stems and firm stems and bracts with a firm or imbricate texture (10 points). The packaging characteristics considered the characteristics (1 point for each item) inflorescences in a single plane, inflorescences with medium or small size, inflorescences with intermediate bracts of medium or small size, light or intermediate 
inflorescences, less than 10 flowers/bracts, thin or intermediate floral stems, firm stems, bracts with firm texture or imbricated, possibility of commercialization in boxes, which included the combined evaluation of the size, height and plan of insertion of the bracts (9 points). The transportation characteristics considered were (1 point for each item) inflorescences in a single plane, inflorescences with little or without wax; medium or small size inflorescences, inflorescences with intermediate bracts of medium or small size, light or intermediate inflorescences; less than 10 flowers/bracts; thin or intermediate floral stems; bracts with a firm or imbricated texture, firm stems, possibility of commercialization in boxes that included the combined evaluation of the size, height and insertion plan of the bracts (10 points). Extra points ( 3 points) was given to species with bracts with a firm or imbricated texture for simplifying harvesting and marketing processes, species with dark color bracts such as purple or red for delaying signs of senescence, and with a high post-harvest longevity for increasing marketing period. The maximum score obtained for a species was 52 points. The application of the scale of points allowed the definition of the species as little suitable (below 13), moderately suitable (between 13 and 39) and very suitable (above 39) for use as cut flowers.

\section{Results and Discussion}

The species (Figure 1), classified in 10, of the 11 Sections of the subgenus Griggsia, namely, Griggsia, Barbatae, Longae, Obscurae, Dromedarius, Sigmoideae, Rostratae, Pendulae, Contortex and Retiformes showed a musoid habit, and $H$. juruana, presented a canoid growth habit, according to Watson and Smith (1979).

$H$. magnifica, $H$. revoluta, $H$. villosa, $H$. mutisiana, $H$. obscura and $H$. stella-maris growth better on sites with intense shade. $H$. ramonensis, $H$. chartacea, $H$. flabellata, $H$. marginata and $H$. rostrata growth better on sites under full sun (Table 3).

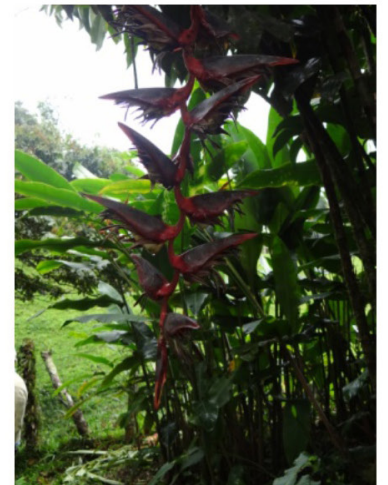

H. griggsiana

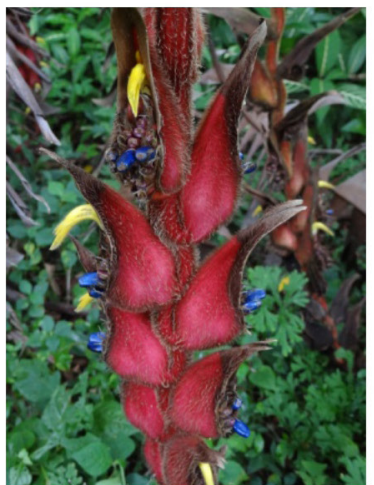

H. magnifica

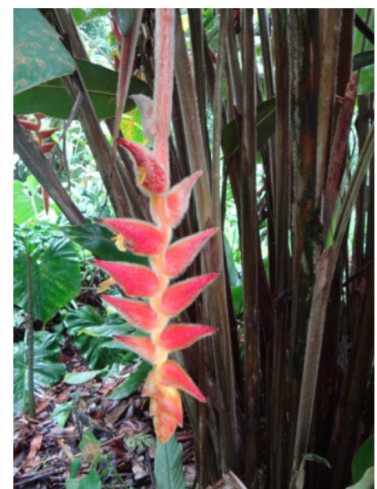

H. pogonantha

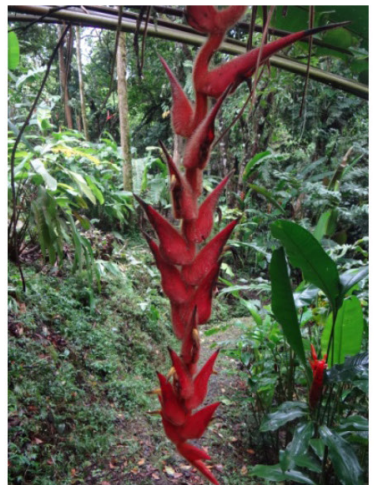

H. ramonensis

Figure 1. Heliconia with pending inflorescences evaluated to define the suitability for commercialization as cut flower. 


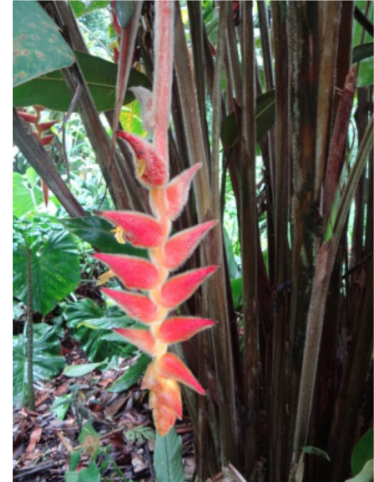

H. regalis

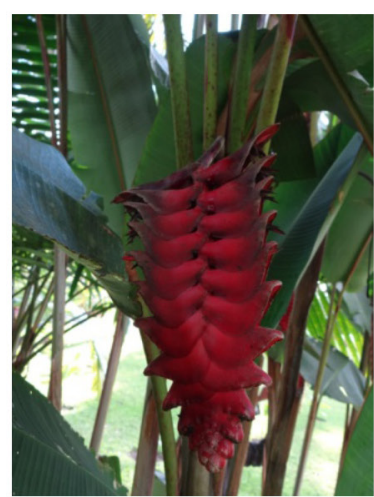

H. mariae

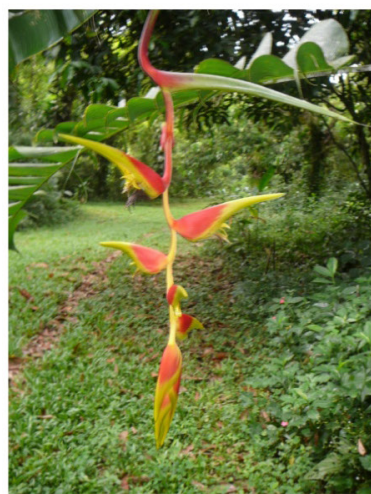

H. fernandezii

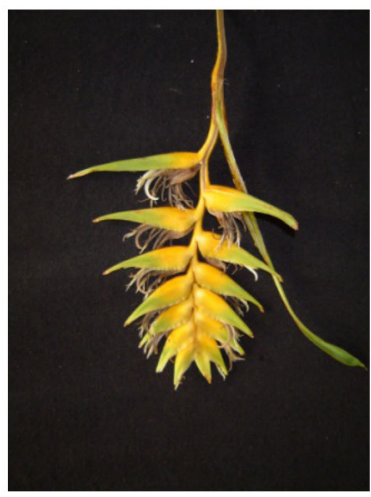

H. villosa

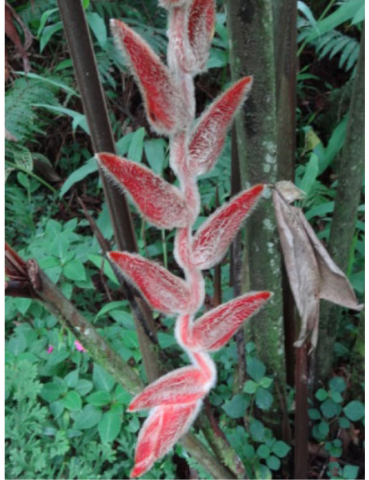

H. vellerigera

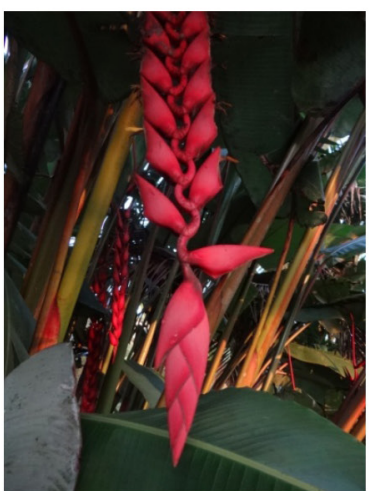

H. stilesii

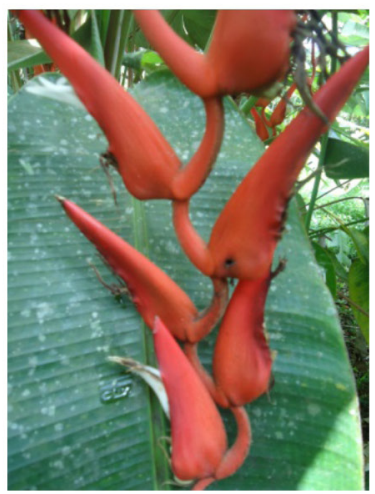

H. pendula

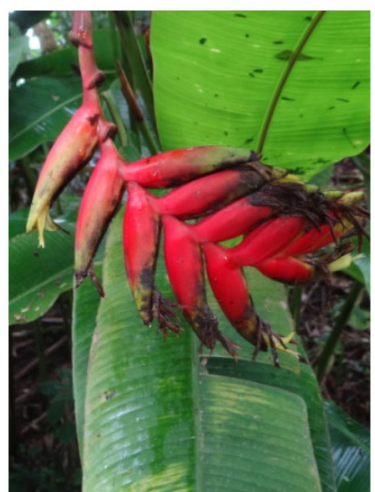

H. flabellata

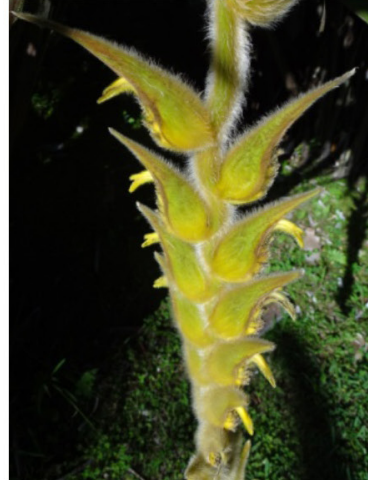

H. xanthovillosa

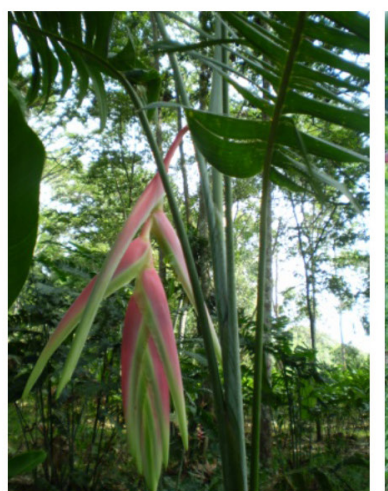

H. chartaceae 'Sexy Pink'

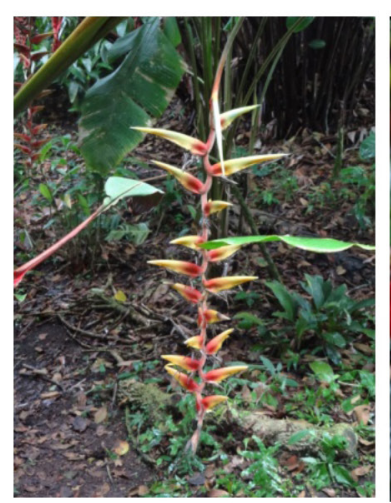

H. platystachys

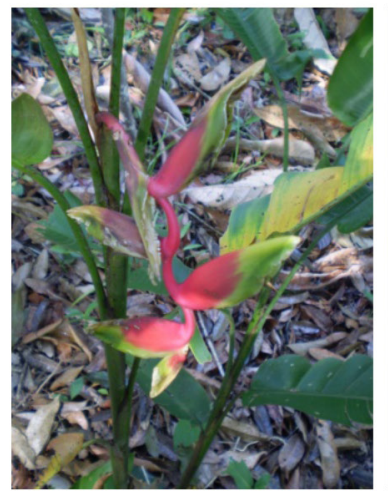

H. juruana

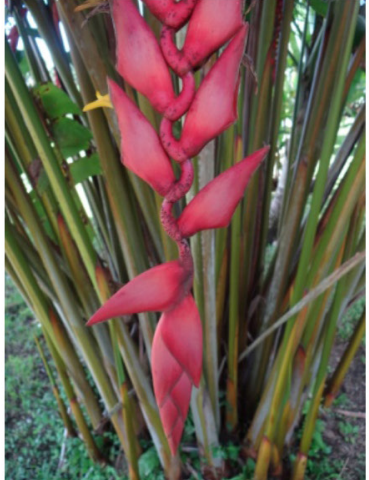

H. longissima

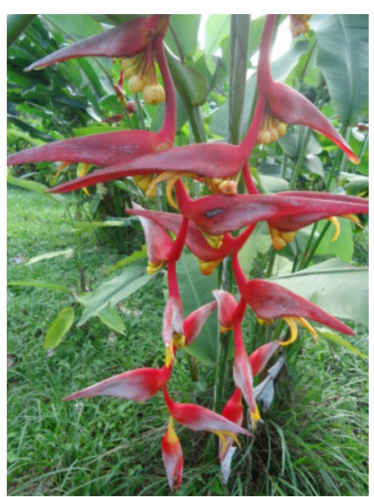

H. collinsiana

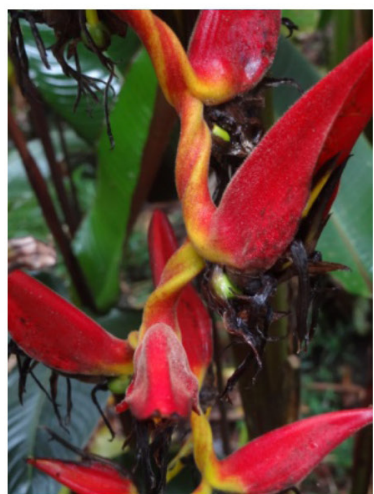

H. revoluta

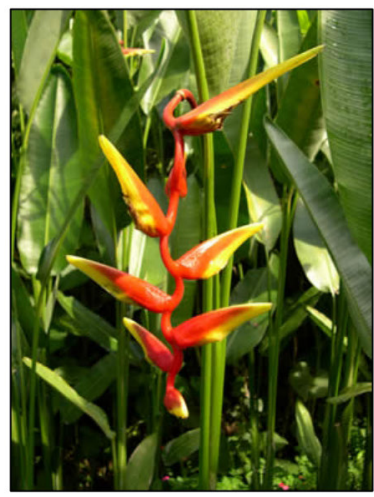

H. marginata

Figure 1. cont. 


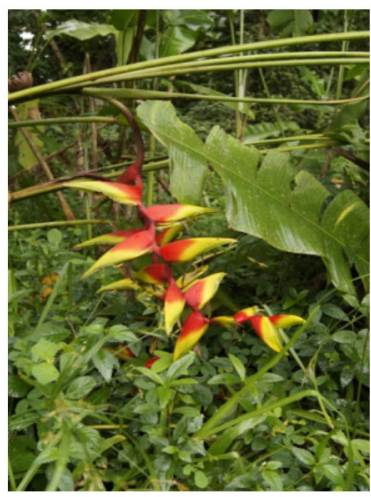

H. rauliniana

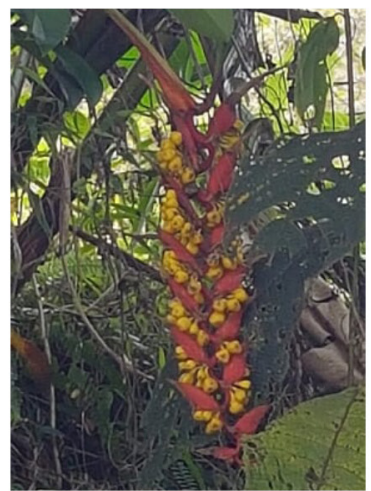

H. dielsiana

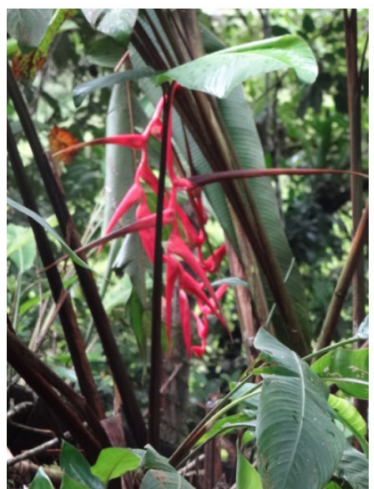

H. trichocarpa

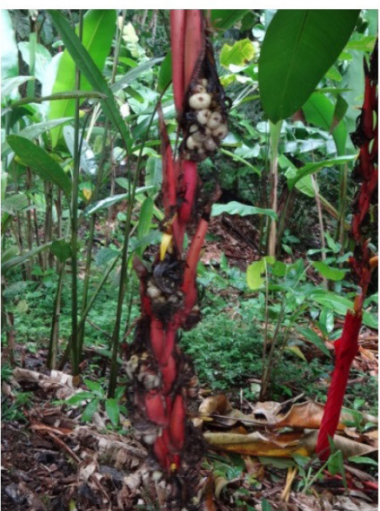

H. obscura

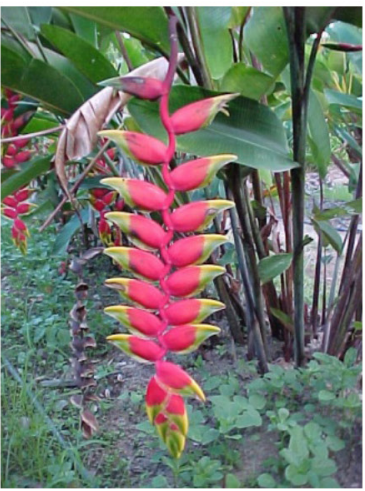

H. rostrata

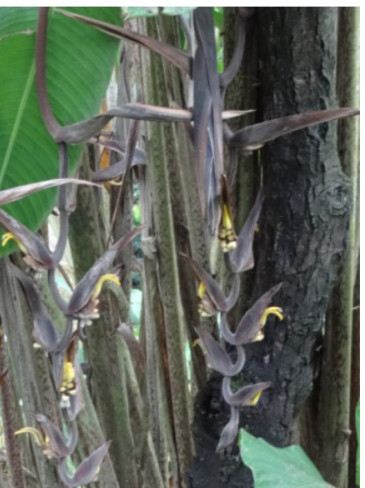

H. necrobracteata

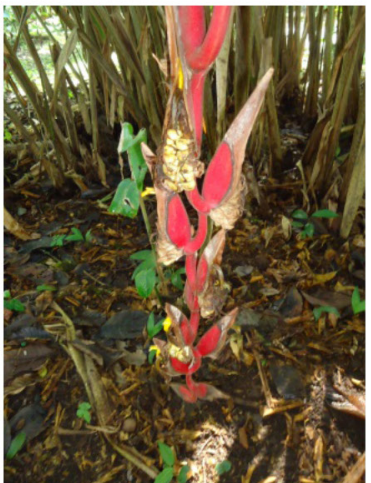

H. combinata

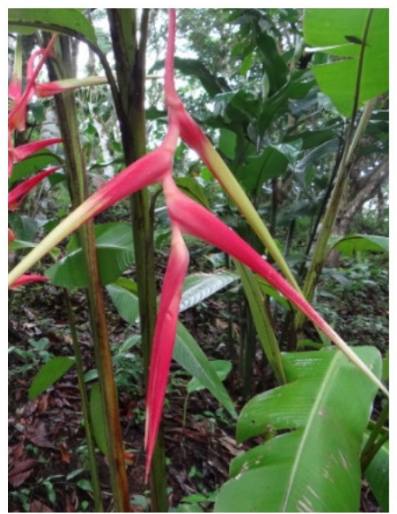

H. nutans

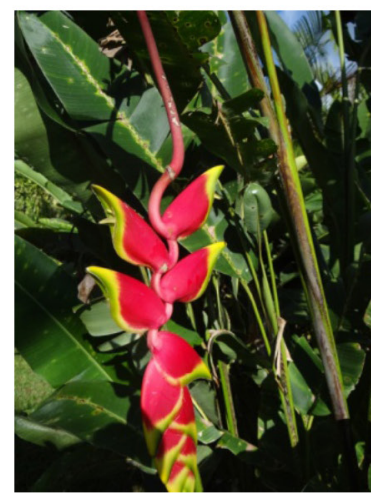

H. standleyi

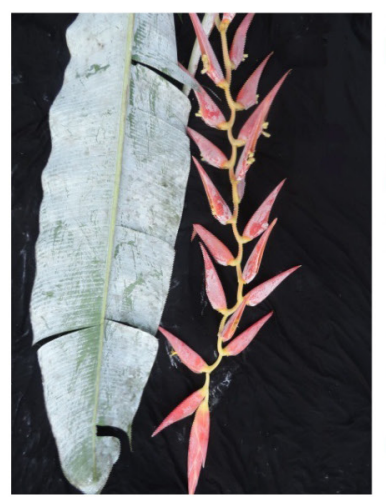

H. penduloides

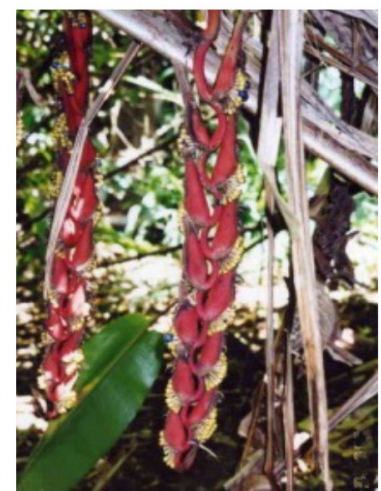

H. laxa

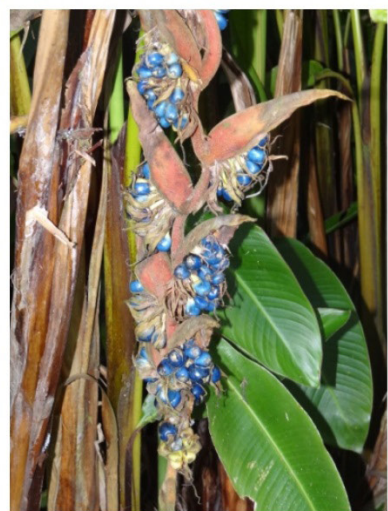

$H$. huilensis

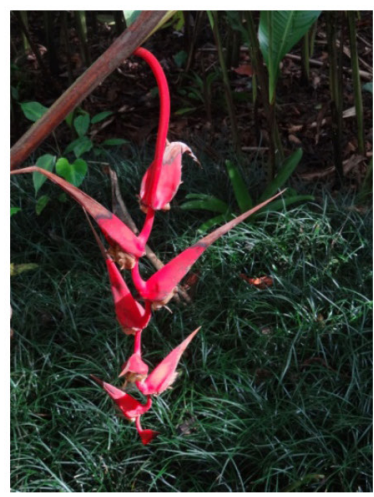

H. colgantea

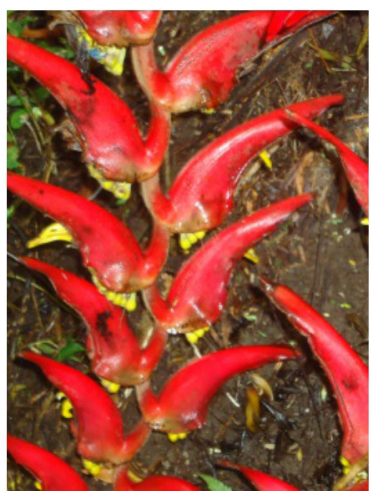

H. reptans

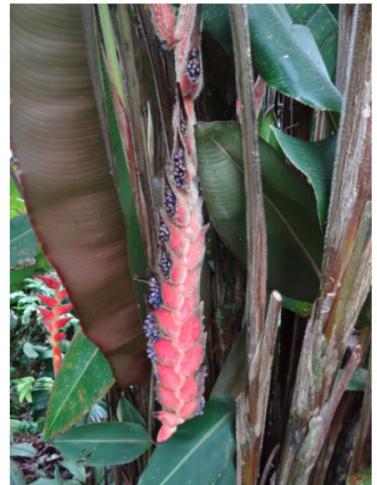

H. mutisiana

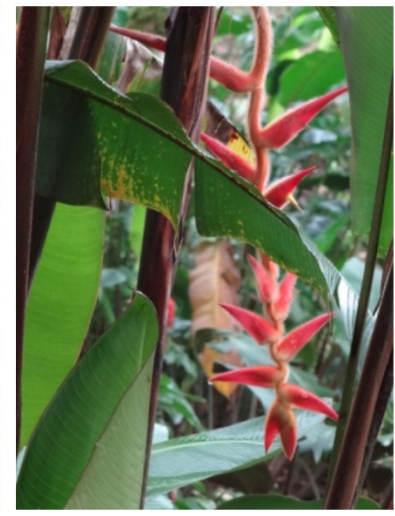

H. stella-maris

Figure 1. cont. 
Table 3. Data referring to the general characteristics of the plants of 36 Heliconia species.

\begin{tabular}{|c|c|c|c|c|c|c|c|}
\hline Specie & Section & $\begin{array}{l}\text { Habit } \\
\text { of the } \\
\text { plant }\end{array}$ & $\begin{array}{l}\text { Preferential } \\
\text { exposure }\end{array}$ & $\begin{array}{l}\text { Moisture of the } \\
\text { soil }\end{array}$ & $\begin{array}{l}\text { Sprouting and } \\
\text { occupied area } \\
\qquad\left(\mathrm{m}^{2}\right)\end{array}$ & $\begin{array}{l}\text { Plant } \\
\text { height } \\
\text { (m) }\end{array}$ & $\begin{array}{c}\text { Inflorescence } \\
\text { size }(\mathbf{m})\end{array}$ \\
\hline H. griggsiana & Griggsia & musoid & Half shade & Medium & Medium (2.2) & $5-6$ & 1.2 \\
\hline H. magnifica & Barbatae & musoid & Shade & High & High (3.2) & $4-6$ & 0.95 \\
\hline H. pogonantha & Barbatae & musoid & Half shade & High & High (2.7) & $4-7.5$ & 1.6 \\
\hline H. ramonensis & Barbatae & musoid & Full sun & Medium to High & High (2.6) & $2.5-6$ & 0.9 \\
\hline H. regalis & Barbatae & musoid & Half shade & Medium & High (2.7) & 4-6 & 1.0 \\
\hline H. vellerigera & Barbatae & musoid & Half shade & High & High (3.2) & $4-7$ & $1.0-1.5$ \\
\hline H. xanthovillosa & Barbatae & musoid & Half shade & High & High (3.6) & $3.5-4.5$ & 0.86 \\
\hline H. longissima & Longae & musoid & Half shade & Medium & High (2.4) & $2-4$ & $1.8-2.1$ \\
\hline H. mariae & Longae & musoid & Half shade & High & Medium (2.3) & $4-7.5$ & 0.65 \\
\hline H. stilesii & Longae & musoid & Half shade & High & High (2.6) & $5-6$ & 1.0 \\
\hline H. chartaceae & Pendulae & musoid & Full sun & High & High (2.6) & $2-4$ & 0.40 a 1.20 \\
\hline H. collinsiana & Pendulae & musoid & Half shade & Medium & High (3.1) & $4-6$ & 0.72 \\
\hline H. fernandezii & Pendulae & musoid & Half shade & High & Medium (2.2) & $4-5$ & $0.85-1.1$ \\
\hline H. pendula & Pendulae & musoid & Half shade & High & Medium (2.2) & $2.5-4.5$ & $0.45-0.95$ \\
\hline H. platystachys & Pendulae & musoid & Half shade & High & Low (1.7) & $3-4$ & 1.0 \\
\hline H. revoluta & Pendulae & musoid & Shade & High & Medium (2.1) & $2-3$ & $0.45-0.6$ \\
\hline H. villosa & Pendulae & musoid & Shade & High & Medium (2.0) & $1.5-4$ & $0.25-0.3$ \\
\hline H. flabellata & Rostratae & musoid & Full sun & High & High (2.6) & $1.5-3$ & $0.6-0.8$ \\
\hline H. juruana & Rostratae & canoide & Half shade & High & Medium (2.0) & $2-4$ & 0.46 \\
\hline H. marginata & Rostratae & musoid & Full sun & Extremely High & Low (1.7) & $2-3$ & 0.4 \\
\hline H. rauliniana & Rostratae & musoid & Half shade & High & High (2.5) & $2-3$ & $0.28-0.3$ \\
\hline H. rostrata & Rostratae & musoid & Full sun & Medium & Medium (2.2) & $2-5$ & 0.90 \\
\hline H. standleyi & Rostratae & musoid & Half shade & Medium & Medium (2.2) & $5-6$ & 0.55 \\
\hline H. colgantea & Sigmoideae & musoid & Half shade & High & Media (2.3) & $2-3.5$ & $0.4-0.7$ \\
\hline H. dielsiana & Sigmoideae & musoid & Half shade & High & High (2.4) & $2-4$ & 0.8 \\
\hline $\begin{array}{c}\text { H. necrobrac- } \\
\text { teata }\end{array}$ & Sigmoideae & musoid & Half shade & Medium & Medium (2.0) & $4-4.5$ & $0.4-0.55$ \\
\hline H. penduloides & Sigmoideae & musoid & Half shade & Medium & Low (1.8) & 3 & 0.80 \\
\hline H. reptans & Sigmoideae & musoid & Half shade & High & Medium (2.0) & $1.2-2.2$ & $0.8-1.4$ \\
\hline H. trichocarpa & Sigmoideae & musoid & Half shade & High & Medium (2.3) & $2-4$ & 0.65 \\
\hline H. combinata & Obscurae & musoid & Half shade & High & Medium (2.2) & $2-3.5$ & $0.8-1.6$ \\
\hline H. laxa & Obscurae & musoid & Half shade & High & Medium (2.0) & $1-2$ & $0.6-0.85$ \\
\hline H. mutisiana & Obscurae & musoid & Shade & High & Medium (2.3) & $2.5-4$ & 0.60 \\
\hline H. obscura & Obscurae & musoid & Shade & High & Medium (2.3) & $1.5-2.5$ & 0.50 \\
\hline H. nutans & Contortex & musoid & Half shade & High & Medium (2.0) & $1-2.5$ & 0.55 \\
\hline H. huilensis & Dromedarius & musoid & Half shade & Medium & Medium (2.0) & $1.5-3$ & $0.6-1.3$ \\
\hline H. stella-maris & Retiformes & musoid & Shade & Medium & Medium (2.2) & $1-1.2$ & $0.3-0.6$ \\
\hline
\end{tabular}


Table 4. The characteristics of the rachis, bracts and flowers of 36 species of Heliconia.

\begin{tabular}{|c|c|c|c|c|c|c|c|}
\hline Specie & $\begin{array}{c}\text { Type and color of } \\
\text { the rachis }\end{array}$ & $\begin{array}{c}\text { Number, } \\
\text { insertion plan } \\
\text { and imbricate } \\
\text { bracts }\end{array}$ & $\begin{array}{l}\text { Length of } \\
\text { intermediate } \\
\text { bracts }(\mathrm{cm}) \\
\text { and texture }\end{array}$ & $\begin{array}{l}\text { Hairiness } \\
\text { of bracts }\end{array}$ & $\begin{array}{l}\text { Wax on } \\
\text { bracts }\end{array}$ & $\begin{array}{l}\text { Color of the } \\
\text { bracts }\end{array}$ & $\begin{array}{l}\text { Number } \\
\text { of flowers/ } \\
\text { bracts }\end{array}$ \\
\hline H. griggsiana & $\begin{array}{c}\text { Sinuous } \\
\text { Red, sometimes } \\
\text { yellow }\end{array}$ & $\begin{array}{c}13-28 \\
\text { Diverse plans } \\
\text { Free }\end{array}$ & $\begin{array}{l}15-18 \\
\text { Firm }\end{array}$ & Few & Very & $\begin{array}{l}\text { Green with base } \\
\text { and borders } \\
\text { yellow, or reds } \\
\text { to dark purple }\end{array}$ & Up to 15 \\
\hline H. magnifica & $\begin{array}{l}\text { Sinuous } \\
\text { red to purple }\end{array}$ & $\begin{array}{c}\text { Up to } 35 \\
\text { Diverse plans } \\
\text { Free }\end{array}$ & $\begin{array}{l}8-10 \\
\text { Firm }\end{array}$ & Very & Without & Red to purple & $10-15$ \\
\hline H. pogonantha & $\begin{array}{l}\text { Sinuous } \\
\text { red to yellow }\end{array}$ & $\begin{array}{c}20-55 \\
\text { Diverse plans } \\
\text { Free }\end{array}$ & $\begin{array}{l}8-12.5 \\
\text { Firm }\end{array}$ & Few & Without & $\begin{array}{c}\text { Red, orange and } \\
\text { yellow }\end{array}$ & 10 a 30 \\
\hline H. ramonensis & $\begin{array}{l}\text { Sinuous } \\
\text { red to pink to } \\
\text { yellow }\end{array}$ & $\begin{array}{c}20 \text { to } 40 \\
\text { Diverse plans } \\
\text { Free }\end{array}$ & $\begin{array}{l}7-11 \\
\text { Firm }\end{array}$ & Very & Without & $\begin{array}{l}\text { Red to pink- } \\
\text { yellow or pink }\end{array}$ & 10 a 30 \\
\hline H. regalis & $\begin{array}{c}\text { Sinuous } \\
\text { yellow, orange } \\
\text { or red }\end{array}$ & $\begin{array}{c}15 \text { to } 30 \\
\text { Diverse plans } \\
\text { Free }\end{array}$ & $\begin{array}{l}18-20 \\
\text { Firm }\end{array}$ & Very & Without & $\begin{array}{l}\text { Orange, red or } \\
\text { pink }\end{array}$ & Up to 20 \\
\hline H. vellerigera & $\begin{array}{l}\text { Very Sinuous } \\
\text { red and hairy with } \\
\text { brown hairs }\end{array}$ & $\begin{array}{c}20-45 \\
\text { Diverse plans } \\
\text { Free }\end{array}$ & $\begin{array}{l}8-12 \\
\text { Firm }\end{array}$ & Very & Without & $\begin{array}{l}\text { Red, woolen, } \\
\text { with wool with } \\
\text { cream color }\end{array}$ & $20-35$ \\
\hline H. xanthovillosa & $\begin{array}{c}\text { Sinuous } \\
\text { shiny yellow }\end{array}$ & $\begin{array}{l}\text { Up to } 35 \\
\text { Same plan } \\
\text { Free }\end{array}$ & $\begin{array}{l}8-10 \\
\text { Firm }\end{array}$ & Very & Without & $\begin{array}{l}\text { Bright yellow } \\
\text { woolen }\end{array}$ & 12 a 20 \\
\hline H. longissima & $\begin{array}{l}\text { Sinuous } \\
\text { red }\end{array}$ & $\begin{array}{c}30-55 \\
\text { Diverse plans } \\
\text { Free }\end{array}$ & $\begin{array}{l}10-14 \\
\text { Firm }\end{array}$ & Without & Few & Red & 11 a 18 \\
\hline H. mariae & $\begin{array}{l}\text { Little Sinuous } \\
\text { red yellow }\end{array}$ & $\begin{array}{c}\text { 40-65 } \\
\text { Same plan } \\
\text { Imbricate }\end{array}$ & $\begin{array}{l}5-6.5 \\
\text { Firm }\end{array}$ & Without & Few & Pink to red & $20-30$ \\
\hline H. stilesii & $\begin{array}{l}\text { Very Sinuous } \\
\text { red }\end{array}$ & $\begin{array}{c}20-35 \\
\text { Same plan } \\
\text { Free }\end{array}$ & $\begin{array}{l}8.5-9 \\
\text { Firm }\end{array}$ & Few & Few & $\begin{array}{l}\text { Pink-red, } \\
\text { pubescent. }\end{array}$ & $10-20$ \\
\hline H. chartaceae & $\begin{array}{c}\text { Sinuous } \\
\text { Pink or red }\end{array}$ & $\begin{array}{c}\text { 14-18 } \\
\text { Diverse plans } \\
\text { Free }\end{array}$ & $\begin{array}{c}13-20 \\
\text { Flaccid }\end{array}$ & Without & Very & $\begin{array}{l}\text { Red or pink } \\
\text { with borders } \\
\text { pink or green }\end{array}$ & 12 \\
\hline H. collinsiana & $\begin{array}{l}\text { Sinuous } \\
\text { red, sometimes } \\
\text { yellow }\end{array}$ & $\begin{array}{c}\text { 7-18 } \\
\text { Diverse plans } \\
\text { Free }\end{array}$ & $\begin{array}{c}15-20 \\
\text { Flaccid }\end{array}$ & Without & Very & Orange-red & $15-20$ \\
\hline H. fernandezii & $\begin{array}{l}\text { Sinuous } \\
\text { red }\end{array}$ & $\begin{array}{l}15 \text { to } 20 \\
\text { Diverse plans } \\
\text { Free }\end{array}$ & $\begin{array}{l}10 \text { a } 12 \\
\text { Firm }\end{array}$ & Without & Few & $\begin{array}{c}\text { Red, with } \\
\text { yellow borders }\end{array}$ & 10 \\
\hline H. pendula & $\begin{array}{l}\text { Strait } \\
\text { red }\end{array}$ & $\begin{array}{c}8-15 \\
\text { Diverse plans } \\
\text { Free }\end{array}$ & $\begin{array}{c}13-14 \\
\text { Flaccid }\end{array}$ & Without & Very & Red & $10-15$ \\
\hline H. platystachys & $\begin{array}{l}\text { Little Sinuous } \\
\text { red and becoming } \\
\text { yellow near the } \\
\text { terminal bracts }\end{array}$ & $\begin{array}{c}10-20 \\
\text { Diverse plans } \\
\text { Free }\end{array}$ & $\begin{array}{l}11 \text { a } 16 \\
\text { Firm }\end{array}$ & Very & Without & $\begin{array}{l}\text { Red on base, } \\
\text { yellow Apex } \\
\text { and small spots } \\
\text { on the sides }\end{array}$ & $6-15$ \\
\hline
\end{tabular}


Table 4. cont.

\begin{tabular}{|c|c|c|c|c|c|c|c|}
\hline H. revoluta & $\begin{array}{l}\text { Very Sinuous } \\
\text { red }\end{array}$ & $\begin{array}{c}10-15 \\
\text { Diverse plans } \\
\text { Free }\end{array}$ & $\begin{array}{l}8-15 \\
\text { Firm }\end{array}$ & Very & Without & Red & $8-15$ \\
\hline H. villosa & $\begin{array}{c}\text { Sinuous } \\
\text { red or yellow }\end{array}$ & $\begin{array}{c}15 \text { to } 20 \\
\text { Diverse plans } \\
\text { Imbricate }\end{array}$ & $\begin{array}{l}14-20 \\
\text { Firm }\end{array}$ & Very & Without & Red or yellow & 10 a 12 \\
\hline H. flabellata & $\begin{array}{l}\text { Sinuous } \\
\text { red-orange }\end{array}$ & $\begin{array}{c}4-8 \\
\text { Diverse plans } \\
\text { Free }\end{array}$ & $\begin{array}{c}\text { 7-7.5 } \\
\text { Flaccid }\end{array}$ & Very & Without & $\begin{array}{l}\text { Red with Apex } \\
\text { and borders } \\
\text { yellow-green }\end{array}$ & $7-9$ \\
\hline H. juruana & $\begin{array}{l}\text { Sinuous } \\
\text { with } \\
\text { red marks }\end{array}$ & $\begin{array}{c}10-30 \\
\text { Diverse plans } \\
\text { Free }\end{array}$ & $\begin{array}{l}5-7 \\
\text { Flaccid }\end{array}$ & Few & Without & $\begin{array}{l}\text { Red and one- } \\
\text { third yellow- } \\
\text { greenish on the } \\
\text { upper third of } \\
\text { apex }\end{array}$ & $3-4$ \\
\hline H. marginata & $\begin{array}{l}\text { Sinuous } \\
\text { red }\end{array}$ & $\begin{array}{c}\text { 9-15 } \\
\text { Diverse plans } \\
\text { Free }\end{array}$ & $\begin{array}{l}7-9.5 \\
\text { Firm }\end{array}$ & Without & Without & $\begin{array}{l}\text { Red with yellow } \\
\text { borders or } \\
\text { greenish apex }\end{array}$ & $7-15$ \\
\hline H. rauliniana & $\begin{array}{l}\text { Sinuous } \\
\text { red }\end{array}$ & $\begin{array}{c}\text { 7-10 } \\
\text { Diverse plans } \\
\text { Free }\end{array}$ & $\begin{array}{l}10-15 \\
\text { Firm }\end{array}$ & Few & Without & $\begin{array}{c}\text { Red with } \\
\text { yellow borders } \\
\text { with green } \\
\text { stretch marks }\end{array}$ & $2-3$ \\
\hline H. rostrata & $\begin{array}{l}\text { Sinuous } \\
\text { red }\end{array}$ & $\begin{array}{c}18-25 \\
\text { Same plan } \\
\text { Free }\end{array}$ & $\begin{array}{l}7-9.5 \\
\text { Firm }\end{array}$ & Few & Without & $\begin{array}{l}\text { Red with yellow } \\
\text { or green borders }\end{array}$ & $2-5$ \\
\hline H. standleyi & $\begin{array}{c}\text { Straight to Sinuous } \\
\text { red }\end{array}$ & $\begin{array}{c}11 \text { to } 25 \\
\text { Diverse plans } \\
\text { Free }\end{array}$ & $\begin{array}{l}7-9.0 \\
\text { Firm }\end{array}$ & Few & Without & $\begin{array}{c}\text { Red with } \\
\text { yellow-green } \\
\text { borders }\end{array}$ & $2-5$ \\
\hline H. colgantea & $\begin{array}{l}\text { Sinuous } \\
\text { pink }\end{array}$ & $\begin{array}{c}8-10 \\
\text { Diverse plans } \\
\text { Free }\end{array}$ & $\begin{array}{l}8-12.0 \\
\text { Flaccid }\end{array}$ & Few & Without & $\begin{array}{l}\text { Dark pink with } \\
\text { green tones }\end{array}$ & Up to 15 \\
\hline H. dielsiana & $\begin{array}{l}\text { Sinuous } \\
\text { red orange or } \\
\text { yellow }\end{array}$ & $\begin{array}{l}\text { 18-25 } \\
\text { Same plan } \\
\text { Free }\end{array}$ & $\begin{array}{c}10-13.5 \\
\text { Firm }\end{array}$ & Very & Without & $\begin{array}{l}\text { Orange-red to } \\
\text { red }\end{array}$ & $10-15$ \\
\hline $\begin{array}{c}H . \\
\text { necrobracteata }\end{array}$ & $\begin{array}{l}\text { Sinuous } \\
\text { dark red }\end{array}$ & $\begin{array}{c}10-20 \\
\text { Diverse plans } \\
\text { Free }\end{array}$ & $\begin{array}{c}7-8 \\
\text { Firm }\end{array}$ & Few & Without & $\begin{array}{l}\text { Red becoming } \\
\text { necrotic right } \\
\text { after anthesis }\end{array}$ & 10 a 30 \\
\hline H. penduloides & $\begin{array}{l}\text { Sinuous } \\
\text { pink }\end{array}$ & $\begin{array}{c}20-25 \\
\text { Diverse plans } \\
\text { Free }\end{array}$ & $\begin{array}{l}10-14 \\
\text { Flaccid }\end{array}$ & Without & Very & Pinky & 10 a 30 \\
\hline H. reptans & $\begin{array}{l}\text { Sinuous } \\
\text { red brown }\end{array}$ & $\begin{array}{c}\text { 34-45 } \\
\text { Same plan } \\
\text { Free }\end{array}$ & $\begin{array}{l}7-11 \\
\text { Firm }\end{array}$ & Without & Without & Red-brown & Up to 20 \\
\hline H. trichocarpa & $\begin{array}{l}\text { Sinuous } \\
\text { red }\end{array}$ & $\begin{array}{c}\text { 6-11 } \\
\text { Diverse plans } \\
\text { Free }\end{array}$ & $\begin{array}{c}10-12 \\
\text { Flaccid }\end{array}$ & Without & Without & Pinky & $20-35$ \\
\hline H. combinata & $\begin{array}{l}\text { Sinuous } \\
\text { red }\end{array}$ & $\begin{array}{c}15-45 \\
\text { Diverse plans } \\
\text { Free }\end{array}$ & $\begin{array}{l}8.5-10 \\
\text { Firm }\end{array}$ & Very & Without & $\begin{array}{c}\text { Red with early } \\
\text { necrotic margins }\end{array}$ & 12 a 20 \\
\hline H. laxa & $\begin{array}{l}\text { Sinuous } \\
\text { red }\end{array}$ & $\begin{array}{c}18 \\
\text { Same plan } \\
\text { Free }\end{array}$ & $\begin{array}{l}8-13 \\
\text { Firm }\end{array}$ & Very & Without & Red & 11 a 18 \\
\hline H. mutisiana & $\begin{array}{l}\text { Sinuous } \\
\text { red-orange }\end{array}$ & $\begin{array}{c}16-20 \\
\text { Same plan } \\
\text { Imbricate }\end{array}$ & $\begin{array}{l}8.5-10 \\
\text { Firm }\end{array}$ & Very & Without & Red to orange & $20-30$ \\
\hline
\end{tabular}


Table 4. cont.

\begin{tabular}{|c|c|c|c|c|c|c|c|}
\hline H. obscura & $\begin{array}{l}\text { Sinuous } \\
\text { red or yellow- } \\
\text { green }\end{array}$ & $\begin{array}{c}10-14 \\
\text { Diverse plans } \\
\text { Free }\end{array}$ & $\begin{array}{l}10-12 \\
\text { Firm }\end{array}$ & Very & Without & $\begin{array}{c}\text { Red opaque } \\
\text { with black } \\
\text { necrotic apexes }\end{array}$ & $10-20$ \\
\hline H. nutans & $\begin{array}{l}\text { Sinuous } \\
\text { red to red-orange }\end{array}$ & $\begin{array}{c}5-13 \\
\text { Diverse plans } \\
\text { Free }\end{array}$ & $\begin{array}{l}\text { 7-11 } \\
\text { Flaccid }\end{array}$ & Very & Without & Red-orange & 12 \\
\hline H. huilensis & $\begin{array}{l}\text { Sinuous } \\
\text { red }\end{array}$ & $\begin{array}{c}12-20 \\
\text { Same plan } \\
\text { Free }\end{array}$ & $\begin{array}{l}10-16 \\
\text { Firm }\end{array}$ & Very & Without & Red & $15-20$ \\
\hline H. stella-maris & $\begin{array}{l}\text { Sinuous } \\
\text { red-orange }\end{array}$ & $\begin{array}{c}14-28 \\
\text { Diverse plans } \\
\text { Free }\end{array}$ & $\begin{array}{l}10-24 \\
\text { Firm }\end{array}$ & Very & Without & Red & 10 \\
\hline
\end{tabular}

The texture of the bracts was evaluated by the resistance of the bract to a light pressure applied by fingers. The insertion of bracts impacts inflorescence harvesting, handling and transport, but above all, it is important in packaging process, as inflorescences with bracts in different planes difficult the packing in boxes and cause less resistance during transport, causing friction between inflorescences, causing damage to the inflorescences reducing its quality. H. xanthovillosa, $H$. mariae, $H$. stilesii, $H$. rostrata, $H$. dielsiana, $H$. reptans, $H$. laxa, $H$. mutisiana and $H$. huilensis have inflorescences with bracts distributed in a single same plane.

Size and texture of the intermediate bracts have similar influences and consequences on the most varied procedures (Loges et al., 2014). H. collinsiana, $H$. rauliniana, $H$. colgantea, $H$. dielsiana and $H$. stela-maris have large intermediate bracts. The procedures between harvesting and transport resistance were also affected by the flaccid texture of intermediate bracts that are very susceptible to physical injuries, commoly seen in $H$. chartacea, $H$. collinsiana, $H$. pendula, H. flabellata, H. juruana, $H$. colgantea, $H$. penduloides, $H$. trichocarpa and $H$. nutans.

Hairiness is a factor that improves the ornamental aspect of the inflorescence; however, its difficult handling, once insects and dirt can be retained among the hairs, requiring a more meticulous cleaning process. The species showed varying degrees of hairiness, as well as the absence of hair in several. The presence of wax on the bracts does not only affect the packaging process. Waxiness can come off the bract during the handling and harvesting process, causing stained areas and can cause stains on contiguous flower stems in the same package during transport. H. chartacea, $H$. collinsiana, $H$. pendula and $H$. penduloides showed high quantities of wax on the inflorescences.

The color of rachis and bracts are attributes that valorize the ornamental aspects of heliconia inflorescences, either for the intense and vibrant colors, or for the contrast of the mixture of colors. Damages resulting from friction occurred in the different stages between harvest and commercialization are more evident on inflorescences with yellow or pink bracts as occurs in $H$. chartacea, $H$. xanthovillosa, H. colgantea, $H$. penduloides and $H$. trichocarpa. The main indicator of this damage was the darkening of the affected area.

The diameter of the floral stem can be associated with complications in harvesting, handling, packaging and transporting, once stems with larger diameter difficult and slow these processes. The species that had disadvantaged due to large stem diameter were $H$. magnifica, $H$. vellerigera, $H$. xanthovillosa, $H$. mariae, $H$. stilesii, $H$. dielsiana, H. mutisiana, H. obscura, $H$. nutans, and $H$. huilensis (Table 5). 
Table 5. Characteristics of inflorescences and flower stems of 36 Heliconia species.

\begin{tabular}{|c|c|c|c|c|c|c|c|}
\hline Specie & $\begin{array}{l}\text { Diameter of } \\
\text { floral stem } \\
\text { (cm) }\end{array}$ & $\begin{array}{l}\text { Height of } \\
\text { floral stem } \\
\quad \text { (g) }\end{array}$ & $\begin{array}{c}\text { Stem } \\
\text { firmness }\end{array}$ & $\begin{array}{c}\text { Flowering } \\
\text { season }\end{array}$ & $\begin{array}{c}\text { Number of } \\
\text { inflorescences/ } \\
\text { cycle }\end{array}$ & $\begin{array}{l}\text { Senescence signs and } \\
\text { post-harvest longevity } \\
\text { (days) }\end{array}$ & $\begin{array}{c}\text { Purchase } \\
\text { impulse } \\
(\%)\end{array}$ \\
\hline H. griggsiana & $\begin{array}{l}\text { Medium } \\
(1-2 \mathrm{~cm})\end{array}$ & $\begin{array}{c}\text { Heavy } \\
540.0\end{array}$ & Firm & $\begin{array}{l}\text { May to } \\
\text { September }\end{array}$ & $20-35$ & $\begin{array}{c}\text { Fall of flowers, Loss of } \\
\text { brightness, Bracts wilt - } \\
10 \text { (Medium) }\end{array}$ & 78 \\
\hline H. magnifica & $\begin{array}{l}\text { Large } \\
(2.5-4)\end{array}$ & $\begin{array}{l}\text { Heavy } \\
620.0\end{array}$ & Firm & $\begin{array}{l}\text { March to } \\
\text { September }\end{array}$ & $36-48$ & $\begin{array}{l}\text { Loss of brightness, } \\
\text { Extern darkness of } \\
\text { bracts, Bracts wilt - } 12 \\
\text { (Medium) }\end{array}$ & 88 \\
\hline H. pogonantha & $\begin{array}{c}\text { Medium } \\
(1.5-3)\end{array}$ & $\begin{array}{c}\text { Heavy } \\
560.0\end{array}$ & Firm & All year & $40-60$ & $\begin{array}{l}\text { Loss of brightness } \\
\text { Extern darkness of } \\
\text { bracts, Bracts wilt, } \\
\text { Apical dryness - } 14 \\
\text { (High) }\end{array}$ & 92 \\
\hline H. ramonensis & $\begin{array}{l}\text { Medium } \\
(1.1 \text { a } 2)\end{array}$ & $\begin{array}{l}\text { Heavy } \\
520.0\end{array}$ & Firm & All year & $40-60$ & $\begin{array}{l}\text { Loss of brightness, } \\
\text { Extern darkness of } \\
\text { bracts, Bracts wilt - } 10 \\
\text { (Medium) }\end{array}$ & 76 \\
\hline H. regalis & $\begin{array}{l}\text { Medium } \\
(1.5-2.5)\end{array}$ & $\begin{array}{c}\text { Heavy } \\
550.0\end{array}$ & Firm & $\begin{array}{l}\text { May to } \\
\text { August }\end{array}$ & $16-35$ & $\begin{array}{l}\text { Loss of brightness, } \\
\text { Extern darkness of } \\
\text { bracts, Bracts wilt - } 12 \\
\text { (Medium) }\end{array}$ & 96 \\
\hline H. vellerigera & $\begin{array}{c}\text { Large } \\
(2.5-5.0)\end{array}$ & $\begin{array}{c}\text { Heavy } \\
600.0\end{array}$ & Firm & $\begin{array}{l}\text { April to } \\
\text { September }\end{array}$ & $28-50$ & $\begin{array}{l}\text { Loss of brightness, } \\
\text { Extern darkness of } \\
\text { bracts, Bracts wilt - } 12 \\
\text { (Medium) }\end{array}$ & 94 \\
\hline H. xanthovillosa & $\begin{array}{c}\text { Large } \\
(6 \text { a } 6.5)\end{array}$ & $\begin{array}{l}\text { Heavy } \\
620.0\end{array}$ & Firm & $\begin{array}{l}\text { May to } \\
\text { November }\end{array}$ & $30-60$ & $\begin{array}{l}\text { Loss of brightness, } \\
\text { Extern darkness of } \\
\text { bracts, Bracts wilt - } 12 \\
\text { (Medium) }\end{array}$ & 100 \\
\hline H. longissima & $\begin{array}{l}\text { Medium } \\
(1.5-3.0)\end{array}$ & $\begin{array}{l}\text { Heavy } \\
520.0\end{array}$ & Firm & $\begin{array}{l}\text { September } \\
\text { to } \\
\text { December }\end{array}$ & $20-42$ & $\begin{array}{l}\text { Loss of brightness, } \\
\text { Extern darkness of } \\
\text { bracts, Bracts wilt -14 } \\
\text { (High) }\end{array}$ & 92 \\
\hline H. mariae & $\begin{array}{l}\text { Large } \\
(6-8)\end{array}$ & $\begin{array}{c}\text { Heavy } \\
600.0\end{array}$ & Firm & All year & $25-40$ & $\begin{array}{l}\text { Loss of brightness, } \\
\text { Extern darkness of } \\
\text { bracts, Bracts wilt, } \\
\text { Apical dryness - } 14 \\
\text { (High) }\end{array}$ & 76 \\
\hline H. stilesii & $\begin{array}{l}\text { Large } \\
(6-7)\end{array}$ & $\begin{array}{l}\text { Heavy } \\
580.0\end{array}$ & Firm & $\begin{array}{l}\text { June to } \\
\text { September }\end{array}$ & $20-36$ & $\begin{array}{l}\text { Loss of brightness } \\
\text { Extern darkness of } \\
\text { bracts, Bracts wilt - } 10 \\
\text { (Medium) }\end{array}$ & 84 \\
\hline H. chartacea & $\begin{array}{l}\text { Medium } \\
(1.5-2.5)\end{array}$ & $\begin{array}{l}\text { Heavy } \\
520.0\end{array}$ & Firm & $\begin{array}{l}\text { August to } \\
\text { January }\end{array}$ & $24-40$ & $\begin{array}{c}\text { Fall of flowers, } \\
\text { Loss of brightness, } \\
\text { Extern and intern } \\
\text { darkness of bracts, } \\
\text { Bracts wilt, Borders wilt, } \\
\text { fall of bracts - } 15 \text { (High) }\end{array}$ & 100 \\
\hline H. collinsiana & $\begin{array}{c}\text { Medium } \\
(2.5-3)\end{array}$ & $\begin{array}{c}\text { Heavy } \\
540.0\end{array}$ & Medium & $\begin{array}{c}\text { January to } \\
\text { August }\end{array}$ & $36-60$ & $\begin{array}{l}\text { Fall of flowers and } \\
\text { fruits, Intern and extern } \\
\text { darkness of bracts, Loss } \\
\text { of brightness, Bracts wilt, } \\
\text { Apical dryness - } 5 \text { (Low) }\end{array}$ & 86 \\
\hline
\end{tabular}


Table 5. cont.

\begin{tabular}{|c|c|c|c|c|c|c|c|}
\hline H. fernandezii & $\begin{array}{l}\text { Medium } \\
(1-2.5)\end{array}$ & $\begin{array}{c}\text { Medium } \\
400.0\end{array}$ & Firm & $\begin{array}{l}\text { October to } \\
\text { February }\end{array}$ & $28-50$ & $\begin{array}{l}\text { Loss of brightness, } \\
\text { Extern darkness of bracts, } \\
\text { Bracts wilt - } 16 \text { (High) }\end{array}$ & 90 \\
\hline H. pendula & $\begin{array}{l}\text { Medium } \\
(1.5-2.5)\end{array}$ & $\begin{array}{c}\text { Medium } \\
320.0\end{array}$ & Medium & $\begin{array}{l}\text { April to } \\
\text { October }\end{array}$ & $16-30$ & $\begin{array}{l}\text { Loss of brightness, } \\
\text { Extern darkness of } \\
\text { bracts, Bracts wilt - } 3 \\
\text { (Low) }\end{array}$ & 68 \\
\hline H. platystachys & $\begin{array}{c}\text { Medium } \\
(1-1.3)\end{array}$ & $\begin{array}{c}\text { Medium } \\
300.0\end{array}$ & Firm & $\begin{array}{l}\text { April to } \\
\text { October }\end{array}$ & $14-20$ & $\begin{array}{l}\text { Loss of brightness, } \\
\text { Extern darkness of } \\
\text { bracts, Bracts wilt, } \\
\text { Borders wilt, Apical } \\
\text { dryness - } 12 \text { (Medium) }\end{array}$ & 86 \\
\hline H. revoluta & $\begin{array}{l}\text { Medium } \\
(1.8-3.0)\end{array}$ & $\begin{array}{c}\text { Heavy } \\
560.0\end{array}$ & Firm & $\begin{array}{l}\text { October to } \\
\text { February }\end{array}$ & $20-36$ & $\begin{array}{c}\text { Loss of brightness, } \\
\text { Extern darkness of } \\
\text { bracts, Bracts wilt - } 9 \\
\text { (Medium) }\end{array}$ & 62 \\
\hline H. villosa & $\begin{array}{l}\text { Medium } \\
(1.5-3.0)\end{array}$ & $\begin{array}{c}\text { Medium } \\
340.0\end{array}$ & Firm & $\begin{array}{l}\text { October to } \\
\text { February }\end{array}$ & $16-24$ & $\begin{array}{l}\text { Loss of brightness, } \\
\text { Extern darkness of } \\
\text { bracts, Bracts wilt - } \\
5 \text { (Low) }\end{array}$ & 54 \\
\hline H. flabellata & $\begin{array}{l}\text { Medium } \\
(2.0-3.0)\end{array}$ & $\begin{array}{c}\text { Medium } \\
420.0\end{array}$ & Firm & $\begin{array}{l}\text { July to } \\
\text { February }\end{array}$ & $25-40$ & $\begin{array}{l}\text { Loss of brightness, } \\
\text { Extern darkness of } \\
\text { bracts, Bracts wilt, } \\
\text { Apical dryness - } 6 \text { (Low) }\end{array}$ & 36 \\
\hline H. juruana & $\begin{array}{c}\text { Large } \\
(2.0-3.2)\end{array}$ & $\begin{array}{l}\text { Light } \\
210.0\end{array}$ & Medium & All year & $20-40$ & $\begin{array}{l}\text { Fall of bracts, Loss } \\
\text { of brightness, Extern } \\
\text { darkness of bracts, } \\
\text { Bracts wilt - } 3 \text { (Low) }\end{array}$ & 38 \\
\hline H. marginata & $\begin{array}{c}\text { Large } \\
(2.0-3.5)\end{array}$ & $\begin{array}{c}\text { Medium } \\
440.0\end{array}$ & Firm & $\begin{array}{l}\text { July and } \\
\text { August }\end{array}$ & $12-20$ & $\begin{array}{l}\text { Loss of brightness, } \\
\text { Extern darkness of } \\
\text { bracts, Bracts wilt, } \\
\text { Apical dryness - } 4 \text { (Low) }\end{array}$ & 42 \\
\hline H. rauliniana & $\begin{array}{l}\text { Medium } \\
(2.0-3.0)\end{array}$ & $\begin{array}{c}\text { Heavy } \\
580.0\end{array}$ & Firm & $\begin{array}{l}\text { November } \\
\text { to } \\
\text { February }\end{array}$ & $24-40$ & $\begin{array}{l}\text { Loss of brightness, } \\
\text { Extern darkness of } \\
\text { bracts, Bracts wilt, Apical } \\
\text { dryness - } 16 \text { (High) }\end{array}$ & 88 \\
\hline H. rostrata & $\begin{array}{c}\text { Large } \\
(1.8-3.5)\end{array}$ & $\begin{array}{c}\text { Medium } \\
410.0\end{array}$ & Firm & All year & $40-70$ & $\begin{array}{l}\text { Loss of brightness, } \\
\text { Extern darkness of } \\
\text { bracts, Bracts wilt, } \\
\text { Withering of the pointer } \\
\text { - } 15 \text { (High) }\end{array}$ & 92 \\
\hline H. standleyi & $\begin{array}{c}\text { Large } \\
(1.5-3.2)\end{array}$ & $\begin{array}{c}\text { Medium } \\
400.0\end{array}$ & Firm & All year & $25-30$ & $\begin{array}{l}\text { Loss of brightness, } \\
\text { Extern darkness of } \\
\text { bracts, Bracts wilt, Fall } \\
\text { of bracts, Withering of } \\
\text { the pointer - } 8 \text { (Medium) }\end{array}$ & 78 \\
\hline H. colgantea & $\begin{array}{l}\text { Medium } \\
(2.0-3.0)\end{array}$ & $\begin{array}{c}\text { Medium } \\
440.0\end{array}$ & Firm & $\begin{array}{l}\text { May to } \\
\text { November }\end{array}$ & $24-40$ & $\begin{array}{l}\text { Loss of brightness, } \\
\text { Extern darkness of } \\
\text { bracts, Bracts wilt, } \\
\text { Borders wilt, Apical } \\
\text { dryness - } 9 \text { (Medium) }\end{array}$ & 68 \\
\hline H. dielsiana & $\begin{array}{c}\text { Large } \\
(2.5-4.0)\end{array}$ & $\begin{array}{c}\text { Medium } \\
480.0\end{array}$ & Firm & $\begin{array}{l}\text { August to } \\
\text { October }\end{array}$ & $15-30$ & $\begin{array}{c}\text { Loss of brightness, } \\
\text { Extern darkness of bracts, } \\
\text { Bracts wilt, } \\
\text { Drop fruits - } 11 \text { (Medium) }\end{array}$ & 78 \\
\hline
\end{tabular}


Table 5. cont.

\begin{tabular}{|c|c|c|c|c|c|c|c|}
\hline $\begin{array}{c}H . \\
\text { necrobracteata }\end{array}$ & $\begin{array}{l}\text { Medium } \\
(1.8-3.0)\end{array}$ & $\begin{array}{c}\text { Medium } \\
320.0\end{array}$ & Firm & $\begin{array}{l}\text { April to } \\
\text { August }\end{array}$ & $20-35$ & $\begin{array}{l}\text { Loss of brightness, } \\
\text { Extern darkness of } \\
\text { bracts, Bracts wilt - } 10 \\
\text { (Medium) }\end{array}$ & 86 \\
\hline H. penduloides & $\begin{array}{l}\text { Medium } \\
(1.5-3.0)\end{array}$ & $\begin{array}{c}\text { Medium } \\
360.0\end{array}$ & Medium & $\begin{array}{l}\text { October to } \\
\text { February }\end{array}$ & $12-20$ & $\begin{array}{l}\text { Loss of brightness, } \\
\text { Extern and intern } \\
\text { darkness of bracts, } \\
\text { Bracts wilt, necrose das } \\
\text { bordas, Apical dryness - } \\
3 \text { (Low) }\end{array}$ & 58 \\
\hline H. reptans & $\begin{array}{l}\text { Medium } \\
(1.0-2.5)\end{array}$ & $\begin{array}{c}\text { Medium } \\
310.0\end{array}$ & Flaccid & $\begin{array}{l}\text { November } \\
\text { to } \\
\text { February }\end{array}$ & $25-30$ & $\begin{array}{l}\text { Loss of brightness, } \\
\text { Extern darkness of } \\
\text { bracts, Bracts wilt - } 10 \\
\text { (Medium) }\end{array}$ & 44 \\
\hline H. trichocarpa & $\begin{array}{l}\text { Medium } \\
(1.4-2.5)\end{array}$ & $\begin{array}{c}\text { Medium } \\
360.0\end{array}$ & Firm & $\begin{array}{c}\text { July to } \\
\text { November }\end{array}$ & $16-25$ & $\begin{array}{l}\text { Loss of brightness, } \\
\text { Extern darkness of } \\
\text { bracts, Bracts wilt, } \\
\text { Borders wilt - } 8 \\
\text { (Medium) }\end{array}$ & 46 \\
\hline H. combinata & $\begin{array}{l}\text { Medium } \\
(1.8-3.0)\end{array}$ & $\begin{array}{c}\text { Heavy } \\
560.0\end{array}$ & Firm & $\begin{array}{l}\text { May to } \\
\text { August }\end{array}$ & $20-30$ & $\begin{array}{l}\text { Loss of brightness, } \\
\text { Extern darkness of } \\
\text { bracts, Bracts wilt, } \\
\text { Borders wilt - } 8 \\
\text { (Medium) }\end{array}$ & 78 \\
\hline H. laxa & $\begin{array}{l}\text { Medium } \\
(2.0-2.8)\end{array}$ & $\begin{array}{l}\text { Heavy } \\
520.0\end{array}$ & Firm & $\begin{array}{l}\text { August to } \\
\text { December }\end{array}$ & $20-35$ & $\begin{array}{l}\text { Loss of brightness, } \\
\text { Extern and intern } \\
\text { darkness of bracts, } \\
\text { Bracts wilt, Borders } \\
\text { wilt, Apical dryness - } 10 \\
\text { (Medium) }\end{array}$ & 68 \\
\hline H. mutisiana & $\begin{array}{c}\text { Large } \\
(2.2-3.5)\end{array}$ & $\begin{array}{c}\text { Heavy } \\
560.0\end{array}$ & Firm & $\begin{array}{l}\text { August to } \\
\text { December }\end{array}$ & $25-32$ & $\begin{array}{l}\text { Loss of brightness, } \\
\text { Extern darkness of } \\
\text { bracts, Bracts wilt } \\
12 \text { (Medium) }\end{array}$ & 52 \\
\hline H. obscura & $\begin{array}{c}\text { Large } \\
(2.5-3.5)\end{array}$ & $\begin{array}{c}\text { Heavy } \\
580.0\end{array}$ & Firm & $\begin{array}{l}\text { October to } \\
\text { February }\end{array}$ & $15-25$ & $\begin{array}{l}\text { Loss of brightness, } \\
\text { Extern darkness of } \\
\text { bracts, Bracts wilt - } 10 \\
\text { (Medium) }\end{array}$ & 32 \\
\hline H. nutans & $\begin{array}{c}\text { Large } \\
(2.2-3.4)\end{array}$ & $\begin{array}{l}\text { Light } \\
240.0\end{array}$ & Firm & $\begin{array}{l}\text { February } \\
\text { to August }\end{array}$ & $18-35$ & $\begin{array}{l}\text { Loss of brightness, } \\
\text { Extern and intern } \\
\text { darkness of bracts, } \\
\text { Bracts wilt, Borders wilt, } \\
\text { Apical dryness - } 3 \text { (Low) }\end{array}$ & 18 \\
\hline H. huilensis & $\begin{array}{c}\text { Large } \\
(2.0-3.4)\end{array}$ & $\begin{array}{l}\text { Light } \\
240.0\end{array}$ & Medium & $\begin{array}{l}\text { August to } \\
\text { October }\end{array}$ & $20-30$ & $\begin{array}{l}\text { Loss of brightness, } \\
\text { Extern darkness of } \\
\text { bracts, Bracts wilt - } 4 \\
\text { (Low) }\end{array}$ & 84 \\
\hline H. stella-maris & $\begin{array}{l}\text { Medium } \\
(2.0-3.0)\end{array}$ & $\begin{array}{l}\text { Light } \\
220.0\end{array}$ & Medium & $\begin{array}{l}\text { October to } \\
\text { February }\end{array}$ & $15-25$ & $\begin{array}{l}\text { Loss of brightness, } \\
\text { Extern darkness of } \\
\text { bracts, Bracts wilt - } 9 \\
\text { (Medium) }\end{array}$ & 54 \\
\hline
\end{tabular}


The inflorescence height is related to the number of stems per package, in addition to hindering other processes from harvest to commercialization (Loges et al., 2005). Exotic shaped cut flowers as Heliconia are packed in way to prevent friction damage during transport (Dubey and Mishra, 2018). Thin inflorescences were observed on $H$. juruana, $H$. nutans, $H$. huilensis and $H$. stella-maris.

The stem firmness is an essential attribute for transport since this process in boxes is not viable and the inflorescences are transported in containers with a capacity of 10-20 inflorescences in vertical position. $H$. collinsiana, $H$. pendula, $H$. juruana, $H$. necrobracteata, $H$. penduloides, $H$. reptans, $H$. huilensis and $H$. stellamaris showed flaccid stems.

The flowering season or period is essential to ensure flower supply to the market, for two main reasons: the offer of products in which few species are commercialized and the period in which the market is supplied. H. pogonantha, $H$. ramonensis, $H$. mariae, $H$. rostrata, $H$. juruana and $H$. standley are produced continuously, the other species have seasonal production that varies from three to eight months. There is a wide variation on Heliconia for vegetative and floral characteristics; thus, different species and varieties have no uniformity on flowering behavior (Malakar and Biswas, 2019).

The number of inflorescences per cycle, a characteristic essential for the proposed selection, as it ensures that market is supplied with products in sufficient quantity and is directly related to plant sprouting. H. magnifica, $H$. pogonantha, $H$. ramonensis, $H$. vellerigera, $H$. xanthovillosa, $H$. collinsiana and $H$. rostrata were very productive species.

Loss of brightness and wilt of the bracts was common for all species evaluated, and most important visual effect of senescence in Heliconia psittacorum L. f. cv. Trópica is wilting or abscission of tepals (Bañuelos-Hernández, 2016). During the senescence process and depending of the species, loss of brightness of the bracts with or without color diminishing, fall of flowers and fruits, internal and/or external darkening of the bracts, necrosis of the edges, dryness of bract apex, wilt and fall of bracts or wilt of the pointer were observed. Post-harvest longevity was over two weeks for $H$. longissima, $H$. mariae, $H$. chartacea, $H$. fernandezii, $H$. rauliniana and H. rostrata. Data is comparable with Heliconia psittacorum x H. spathocircinata cv. Golden Torch (Amaral et al., 2015; Sardinha et al., 2019), and higher than $H$. psittacorum and $H$. densiflora (Silva et al., 2019). The postharvest longevity is one of the leading characteristics of cut flowers that should be considered as pre-requisite for flower quality and selling achievement (Folha et al., 2016).

The data of the morphological and agronomic characterizations and other evaluations (Tables 3, 4, 5), allowed the attribution of points to the inflorescences of the 36 Heliconia species (Table 6). 
Table 6. Scores attributed to the inflorescences of 36 Heliconia species evaluated for recommendation of use as a cut flower.

\begin{tabular}{|c|c|c|c|c|c|c|c|c|c|c|}
\hline Specie & FS & $\mathrm{CP}$ & FS & PHL & H & $\mathbf{P}$ & TE & RT & PI & TOT \\
\hline H. griggsiana & 4 & 3 & 4 & 4 & 6 & 5 & 5 & 2 & 2 & 35 \\
\hline H. magnifica & 4 & 3 & 4 & 4 & 5 & 4 & 5 & 2 & 3 & 34 \\
\hline H. pogonantha & 4 & 3 & 4 & 6 & 6 & 4 & 5 & 3 & 3 & 38 \\
\hline H. ramonensis & 4 & 3 & 4 & 4 & 6 & 5 & 6 & 2 & 2 & 36 \\
\hline H. regalis & 4 & 3 & 4 & 4 & 6 & 5 & 6 & 2 & 3 & 37 \\
\hline H. vellerigera & 4 & 3 & 4 & 4 & 5 & 4 & 5 & 2 & 3 & 34 \\
\hline H. xanthovillosa & 4 & 3 & 4 & 4 & 6 & 5 & 6 & 1 & 3 & 36 \\
\hline H. longissima & 4 & 3 & 4 & 6 & 6 & 3 & 5 & 3 & 3 & 37 \\
\hline H. mariae & 4 & 3 & 4 & 6 & 7 & 5 & 6 & 3 & 2 & 40 \\
\hline H. stilesii & 4 & 3 & 4 & 4 & 7 & 5 & 6 & 2 & 3 & 38 \\
\hline H. chartaceae & 4 & 3 & 4 & 6 & 5 & 4 & 4 & 1 & 3 & 34 \\
\hline H. collinsiana & 4 & 3 & 2 & 2 & 3 & 2 & 2 & 1 & 3 & 22 \\
\hline H. fernandezii & 4 & 3 & 4 & 6 & 9 & 8 & 9 & 3 & 3 & 49 \\
\hline H. pendula & 4 & 2 & 2 & 2 & 5 & 5 & 5 & 1 & 2 & 28 \\
\hline H. platystachys & 4 & 2 & 4 & 4 & 7 & 7 & 8 & 1 & 3 & 40 \\
\hline H. revoluta & 4 & 3 & 4 & 4 & 6 & 5 & 6 & 2 & 2 & 36 \\
\hline H. villosa & 4 & 2 & 4 & 2 & 7 & 7 & 8 & 1 & 2 & 37 \\
\hline H. flabellata & 4 & 3 & 4 & 2 & 7 & 7 & 8 & 1 & 1 & 37 \\
\hline H. juruana & 4 & 3 & 2 & 2 & 6 & 5 & 6 & 1 & 1 & 30 \\
\hline H. marginata & 2 & 2 & 4 & 2 & 7 & 5 & 6 & 1 & 1 & 30 \\
\hline H. rauliniana & 4 & 3 & 4 & 6 & 7 & 5 & 6 & 3 & 3 & 41 \\
\hline H. rostrata & 4 & 3 & 4 & 6 & 9 & 8 & 9 & 3 & 3 & 49 \\
\hline H. standleyi & 4 & 2 & 4 & 4 & 8 & 7 & 8 & 2 & 2 & 41 \\
\hline H. colgantea & 4 & 3 & 4 & 4 & 6 & 4 & 5 & 1 & 2 & 33 \\
\hline H. dielsiana & 2 & 2 & 4 & 4 & 6 & 6 & 7 & 2 & 2 & 35 \\
\hline H. necrobracteata & 4 & 3 & 2 & 4 & 8 & 7 & 8 & 2 & 3 & 41 \\
\hline H. penduloides & 4 & 2 & 2 & 2 & 5 & 4 & 4 & 0 & 2 & 25 \\
\hline H. reptans & 4 & 2 & 0 & 4 & 8 & 7 & 8 & 3 & 2 & 38 \\
\hline H. trichocarpa & 4 & 2 & 4 & 4 & 7 & 5 & 6 & 1 & 2 & 35 \\
\hline H. combinata & 4 & 2 & 4 & 4 & 6 & 5 & 6 & 2 & 2 & 35 \\
\hline H. laxa & 4 & 3 & 4 & 4 & 7 & 7 & 8 & 2 & 2 & 41 \\
\hline H. mutisiana & 4 & 3 & 4 & 4 & 6 & 6 & 7 & 2 & 2 & 38 \\
\hline H. obscura & 4 & 2 & 4 & 4 & 5 & 4 & 5 & 2 & 2 & 32 \\
\hline H. nutans & 4 & 3 & 4 & 2 & 5 & 4 & 5 & 1 & 0 & 28 \\
\hline H. huilensis & 4 & 2 & 2 & 2 & 6 & 6 & 7 & 2 & 3 & 34 \\
\hline H. stella-maris & 4 & 2 & 2 & 4 & 6 & 5 & 6 & 2 & 2 & 33 \\
\hline
\end{tabular}

FS - Flowering season; CP - Clump production; FS - Firmness of stem; PHL - Post-harvest longevity; H - Handling; P - Packaging; TE - Transport easiness; RT - Resistance to transport; PI - Purchase impulse; TOT - Total points. 
The results are compatible with those obtained by Castro (1993) as cited by Loges et al. (2016) for H. chartacea, $H$. collinsiana, $H$. marginata, $H$. pendula, and $H$. rostrata, which were shown to be moderately adequate and by Castro et al. (2007), Loges et al. (2005) and Loges et al. (2016), although the evaluation criteria used in these studies have included a smaller number of parameters evaluated.

Our results demonstrated that all heliconia accessions are suitable for cut flowers use. The species that most stood out as a cut flower were $H$. mariae, $H$. fernandezii, $H$. platystachys, $H$. standley, $H$. necrobracteata and $H$. laxa. $H$. rauliniana and $H$. rostrata were also very suitable as cut flower and are already commercially explored. Some accessions are of species not yet commercially exploited and may increase the demand market for novelties.

\section{Conclusions}

Heliconias with pendent inflorescences can be used as cut flowers, although the processes from harvest to storage are more laborious and there is great variation in postharvest longevity.

\section{Author Contribution}

C.G.: establishment of the research hypothesis, experimental design, implementation of experiments, data collection, data analysis, article writing; C.E.F.C.: establishment of the research hypothesis, experimental design, implementation of experiments, data collection, data analysis, article writing; A.R.T.: data collection, data analysis, article writing; S.M.R.V.: implementation of experiments, maintenance of the experimental area, data collection, data analysis, review of article writing; D.M.: implementation of experiments, maintenance of the experimental area, data collection, data analysis, review of article writing.

\section{References}

AMARAL, G.C.; BECKMANN-CAVALCANTE, M.Z.; BRITO, L.P.D.S.; LIMA, M.P.D.; OSAJIMA, J.A. Conservação de inflorescências de helicônias previamente adubadas com doses crescentes de nitrogênio e potássio. Revista Caatinga, v.28, n.3, p.61-67, 2015. https://doi. org/10.1590/1983-21252015v28n307rc

ANDERSSON, L. Revision of Heliconia sect. Heliconia (Musaceae). Nordian Journal of Botany, v.1, p.759-784, 1981. https://doi.org/10.1111/j.1756-1051.1981.tb01163.x

ANDERSSON, L. Revision of Heliconia subgen. Stenochlamys (Musaceae-Heliconioideae). Opera Botanica, v.82, p.1-123, 1985. https://doi.org/10.1590/ S0102-33061990000100011

ARAÚJO, P.G.P.D.; ALBUQUERQUE FILHO, J.C.C.D.; SILVA, S.S.L.; CASTRO, C.E.F.; GONÇALVES, C.; LOGES, V. Characterization and selection of torch ginger for cut flower. Ornamental Horticulture, v.24, n.4, p.371379, 2018. https://doi.org/10.14295/oh.v24i4.1207
BAÑUELOS-HERNÁNDEZ， K.P.; GARCÍA-NAVA, J.R.; LEYVA-OVALLE, O.R.; PEÑA-VALDIVIA, C.B.; YBARRA-MONCADA, M.C. Flowering stem storage of Heliconia psittacorum L. f. cv. Trópica. Postharvest Biology and Technology, v.112, p.159-169, 2016. https:// doi.org/10.1016/j.postharvbio.2015.10.006

BUZARD, K. Heliconia, Tropical Ginger, Bananas and Canna in Costa Rica. 2019. Available at: https:// traveltoeat.com/heliconia-tropical-ginger-bananas-andcanna-in-costa-rica/ Accessed on: Oct $7^{\text {th }} 2020$.

CASTRO, C.E.F. Helicônias como flores de corte: adequação de espécies e tecnologia pós- colheita. Piracicaba: ESALQ/USP, 1993. 191p.

CASTRO, C.E.F. Helicônia para exportação: aspectos técnicos da produção. FRUPEX. 4ed. Brasília: EMBRAPA, 1995. 44p.

CASTRO, C.E.F.; GONÇALVES, C.; MOREIRA, S.R.; FARIA, O.A. Heliconias brasileiras: características, ocorrência e usos. Revista Brasileira de Horticultura Ornamental, v.17, n.1, p.5-24, 2011. https://doi. org/10.14295/rbho

CASTRO, C.E.F.; MAY, A.; GONÇALVES, C. Espécies de helicônia como flores de corte. Revista Brasileira de Horticultura Ornamental, v.12, p.87-96, 2007. https:// doi.org/10.14295/rbho.v12i2

DIAS, G.M. Quality management of tropical plants. Ornamental Horticulture, v.22, n.3, p.256-258, 2016. https://doi.org/10.14295/oh.v22i3.961

DUBEY, N.; MISHRA, V. Cushioning Materials for Fruits, Vegetables, and Flowers. In: SIDDIQUI, M.W.; RAHMAN, M.S.; WANI, A. (Eds.). Innovative packaging of fruits and vegetables: strategies for safety and quality maintenance. Boca Raton: CRC Press, 2018. 275-313p.

FOLHA, W.R.; SOUZA, R.R.; AMARAL, G.C.; SILVA, A.A.; CARVALHO, J.N.; CAVALCANTE, M.Z.B. Heliconia 'Golden Torch' postharvest: stem ends cutting and renewing vase water benefits. Ornamental Horticulture, v.22, n.2, p.180-185, 2016. https://doi. org/10.14295/oh.v22i2.908.

GOVAERTS, R.; NEWMAN, M.; LOK, J.M. World Checklist of Heliconiacea. Royal Botanic Gardens, Kew. 2016. Avaliable at https://wcsp.science.kew.org/reviewers. do. Accessed on Sept 9th 2020.

KRESS, W.J.; BETANCUR, J.; ECHEVERRY, B. Heliconias - Lhamaradas de la selva colombiana. Bogotá: Cristina Uribe Editores Ltda, 1999. 100p. 
LIMA, R.E.M.; FARIAS, F.C.; BEZERRA, M.A.; BEZERRA, F.C. Parâmetros biométricos e fisiológicos de Heliconia bihai cultivada em região litorânea sob diferentes níveis de radiação solar. Revista Brasileira de Horticultura Ornamental, v.22, n.1, p.50-57, 2016. DOI: https://doi.org/10.14295/oh.v22i1.616

LINARES-GABRIE, A.; RODRÍGUEZ-OROZCO, N.; HERNÁNDEZ-CHONTAL, M.A. Effect of hydration in vase life of two Heliconia cultivars. Ornamental Horticulture, v.25, n.1, p.74-79, 2019. https://doi. org/10.14295/oh.v25i1

LOGES, V.; CASTRO, C.E.F.; CASTRO, A.C.R.; COSTA, A.S.; GONÇALVES, C. Cultivo de helicônias para flor de corte. In: PAIVA, P.D.O.; ALMEIDA, E.F.A. (Org.). Produção de flores de corte. v.2. Lavras: UFLA, 2014. p.206-244.

LOGES, V.; CASTRO, C.E.F.; CASTRO, A.C.R.; GONÇALVES, C. Characteristics of pendent heliconia for use in landscape and as cut flower. Ornamental Horticulture, v.22, n.3, p.287-295, 2016. https://doi. org/10.14295/oh.v22i3.942

LOGES, V.; TEIXEIRA, M.C.F.; CASTRO, A.C.R.; COSTA, A.S. Colheita, pós-colheita e embalagens de flores tropicais em Pernambuco. Horticultura Brasileira, v.23, n.3, p.699-702, 2005. https://doi.org/10.1590/S010205362005000300001

MALAKAR, M.; BISWAS, P.A.S. Study on genetic variability and correlation for floral traits and yield in Heliconia genotypes. Journal of Crop and Weed, v.15, n.1, p.64-72, 2019.
NIHAD, K.; BERWAL, M.K.; HEBBAR, K.B.; BHAT, R.; HARIS, A.A.; RAMESH, S.V. Photochemical and biochemical responses of heliconia (Heliconia stricta 'Iris') to different light intensities in a humid coastal environment. Horticulture, Environment, and Biotechnology, v.60, n.6, p.799-808, 2019. https://doi.org/10.1007/s13580-01900173-1

SARDINHA, D.H.S.; RODRIGUES, A.A.C.; RIBEIRO, S.S.M.; DINIZ, N.B.; NETO, J.R.M.C.; REIS, F.O. Phytostimulants influence the vase life of Heliconia psittacorum cv. golden torch. Postharvest Biology and Technology, v.155, p.140-148, 2019. https://doi. org/10.1016/j.postharvbio.2019.05.001

SILVA, C.G.D.; KRAUSE, S.; BOTINI, A.F.; FRANÇA, R.P.A.D.; SILVA, C.A. Postharvest durability of Heliconiaceae evaluated in a controlled environment in Mato Grosso state, Brazil. Ornamental Horticulture, v.25, n.1, p.80-86, 2019. https://doi.org/10.14295/oh.v25i1.1229

SOUZA, R.R.D.; BECKMANN-CAVALCANTE, M.Z.; SILVA, A.A.; SILVA, E.M.D.; BRITO, L.P.D.S.; SILVA, A.O. Yield and quality of inflorescences of 'Golden Torch' heliconia in different shaded environments. Revista Brasileira de Engenharia Agrícola e Ambiental, v.20, n.2, p.128-132, 2016. https://doi.org/10.1590/1807-1929/ agriambi.v20n2p128-132

WATSON, D.P.; SMITH, R.R. Ornamental Heliconias. Circular 428. Honolulu: Cooperative Extension Service of University of Hawai, 1979. 12p. 